\title{
Architecture Meets Ecology at Arcosanti
}

\section{By Ted Mero}

If you had told me 50 years ago that $I$ would build my activities from the proceeds of wind bells, I would have said you were crazy

_Paolo Soleri
Jeff Stein sits in his apartment built on the edge of a hill in the desert of Central Arizona, 70 miles north of Phoenix. A two-foot by two-foot insulated cabinet door in the corner of his living room opens directly to the highest point of a three-story solar greenhouse that slopes down the south face of his building complex.

When the sun shines on the greenhouse surface, the warm air rises and heats Stein's apartment during the winter months. When Stein opens the cabinet door, he feels the humidified air at double the temperature, a byproduct of the transpiring plants.

"That's good in the dry Arizona desert," Stein says. The dense plant life enriches the air with oxygen. "I'm getting smarter just sitting here." The air is fragrant, too, perfumed by the blossoming plants below. "Believe me when I tell you that everyone should have this experience."

But Stein has little time to sit back and smell the cactus flowers.

His apartment is part of the East Crescent Complex at Arcosanti, a developing, experimental town that began construction in the 1970s under the principles of arcology, a blend of architecture and ecology that demonstrates ways to improve urban conditions while lessening our destructive impact on the earth.

Paolo Soleri, the founder and visionary designer of this urban laboratory, and the president of the parent Cosanti Foundation, retired last fall at age 92, handing the reins over to Stein, a longtime Soleri collaborator and the board of trustees' choice as the foundation's new president.

After spending the better part of three decades away from Arcosanti, most recently working as the dean of the Boston Architectural College, Stein is now tasked with overseeing the continued development of the town while expanding the project's reach to new-and influential-audiences.

\section{The Project}

Some 25,000 tourists visit Arcosanti each year, learning the history and design philosophies of Soleri's urban experiment, while exploring its architectural achievements, from the outdoor amphitheater that plays home to musical performances throughout the summer to the Ceramic Apse that serves as the production center for ceramic wind bells and tiles-a Soleri invention developed in his native Turin, Italy, that has helped keep Arcosanti afloat for more than 30 years. ("If you had told me 50 years ago that I would build my activities from the proceeds of wind bells, I would have said you were crazy," the architect once said.)

The 7,000 individuals who have lived and worked onsite over the course of the project-participating in the hands-on workshops offered at Arcosantihave helped turn Soleri's 22 books and thousands of drawings into a physical reality. Despite the history and many contributions to the effort, however, the town very much remains a work in progress.

"We are not looking around for anything to do," Stein says. "We have projects stacked up, and almost ready to go."

On the front burner are a series of large-scale greenhouses on the side of a hill, much like the test model adjacent to Stein's apartment. Air will release through the bottom of the greenhouses, rising up naturally through a heat duct tunnel to warm the connected buildings. These greenhouses will also be a source of food production for the site.

"Hard to believe, but this will be the first time that anyone has actually built a series of large-scale greenhouses on the side of a hill," Stein notes. "We're in the midst of negotiating with our county planning department on the building of this."

Stein's other immediate proposals include a renovated commercial bakery, a storage unit for Soleri's 
architectural models, and a half-dozen new apartments. Long-term, the hope is to see Arcosanti 5000 to fruition, the master plan to complete a dense ecocity of 5,000 residents, fully stocked with schools, medical support, social spaces, parks, and entertainment spaces.

But Soleri's bells can only generate so much income, and without outside support, it will be difficult for Stein and his team to realize their lofty goals.

Youngsoo Kim, an architectural design and research associate at Arcosanti, has spent much of the past three years with that in mind, translating Soleri's ideas into a tangible medium for the general public while helping bring construction into the 21st century.

"I'm testing existing buildings (at Arcosanti) to see how they are performing in terms of energy," Kim explains. "If the building performs well, we find out the reason in a more scientific way. We could actually update the model and make the building perform that much better by using technology that is now available to us."

Additionally, Kim recently published The Lean Linear City-Arterial Arcology (Cosanti Foundation 2011) a collaborative new investigation of Soleri's idea for a Lean Linear City. The design confronts the necessity to reformulate how we inhabit the planet by creating a complex and immanent solution for the future of the city.

"Arcosanti itself is a meaningful prototype, but it's very difficult to compare; you can't compare it to New York City," Kim says. "That's why I worked to develop Linear City. China, for example, is facing huge urban development pressures as 400 million people move from country to city. We really need a tangible and massive development model.'

\section{Arcology and Sustainability}

Observers tend to associate the sustainability movement with issues like energy savings, or the reduction of food and water waste. And while the construction of Arcosanti certainly considers those elements, the principles behind it have a deeper reach, examining sustainability through the lens of the day-to-day urban lifestyle.

Stein uses the analogy of an elephant and a mouse to explain. Despite the fact that an elephant is 10,000 times larger than a mouse, it only uses 1,000 times the energy. That's because an elephant isn't 10,000 mice, it's a single, designed organism.

"That is the basis of arcology, and we're trying to demonstrate it at Arcosanti," Stein explains. "A city

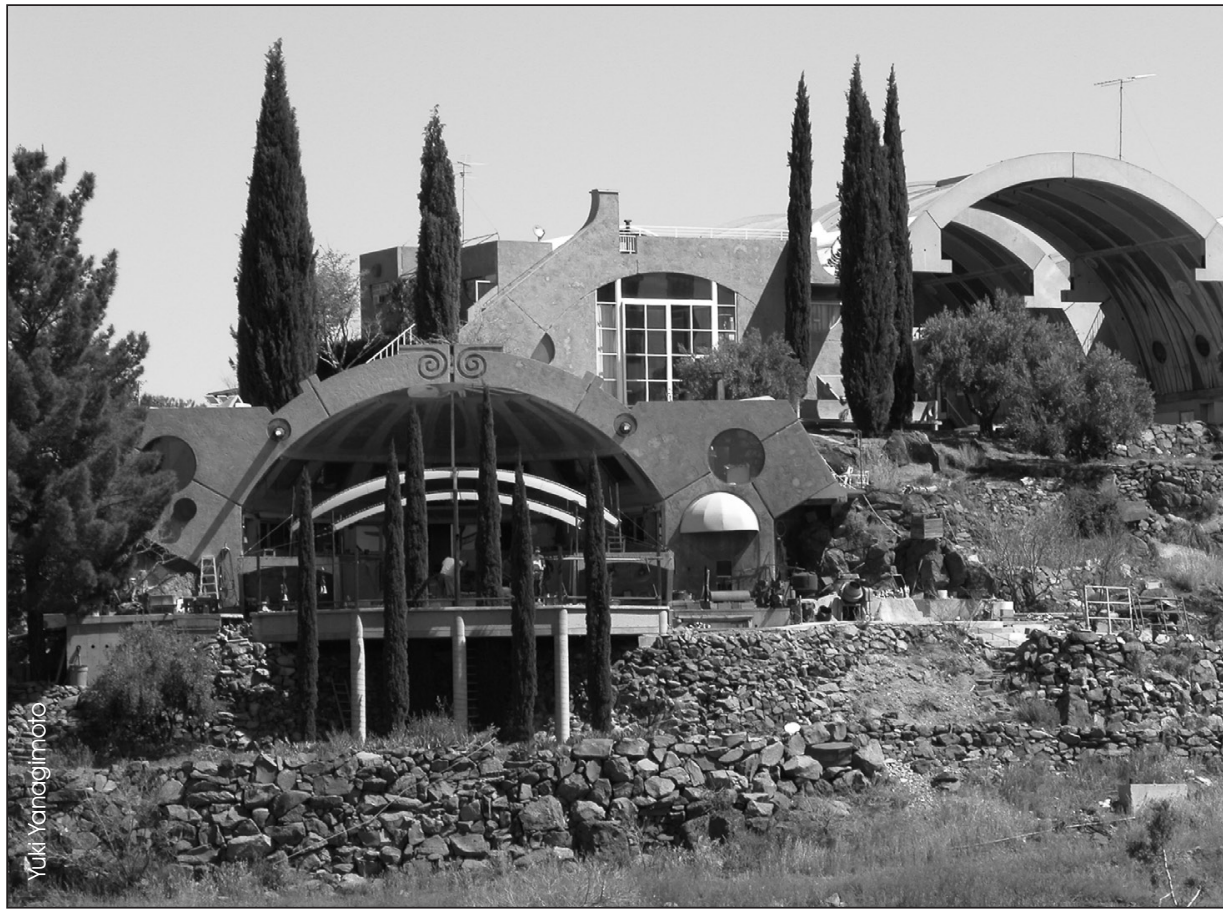

isn't 10,000 separate buildings, each separated by the width of a street and some lawn and sidewalk. But it ought to, as the sort of newest organism on the planet, be designed in a way that mimics the way the successful organisms have been designed, which involves an implosion instead of a continuous sprawl over the landscape."

Translation: A lifestyle in which work, play, and home are all within walking distance.

Cars are not permitted at Arcosanti, as the compacted structure of the town renders them irrelevant. And the series of complex, multifunction buildings covering roughly two acres of land make for easy commuting-Stein's commute to work consists of walking through his apartment door and sliding down a ladder to the floor below. The East Crescent Complex where Stein lives also provides the town's entertainment needs, as it is connected to the amphitheater and performing arts center.

"The complex is an integral urban neighborhood in which the houses aren't lined up against a street that's full of cars and noise and carbon monoxide," Stein says. "So right on everyone's doorstep are some really extraordinary performances by artists, musicians, and actors from around the world.

"It seems to us that sustainability has to do with that, too. It isn't just about saving energy, but it's actually producing a place that is lovable, that intensifies their social interactions, and is a place where they can learn. And we think Arcosanti is certainly becoming that."
Arcosanti's Foundry Apse with West Housing and the Vaults viewed from the south.

\section{Arcosanti itself is}

a meaningful

prototype, but it's

very difficult to

compare; you can't

compare it to

New York City.

-Youngsoo Kim 


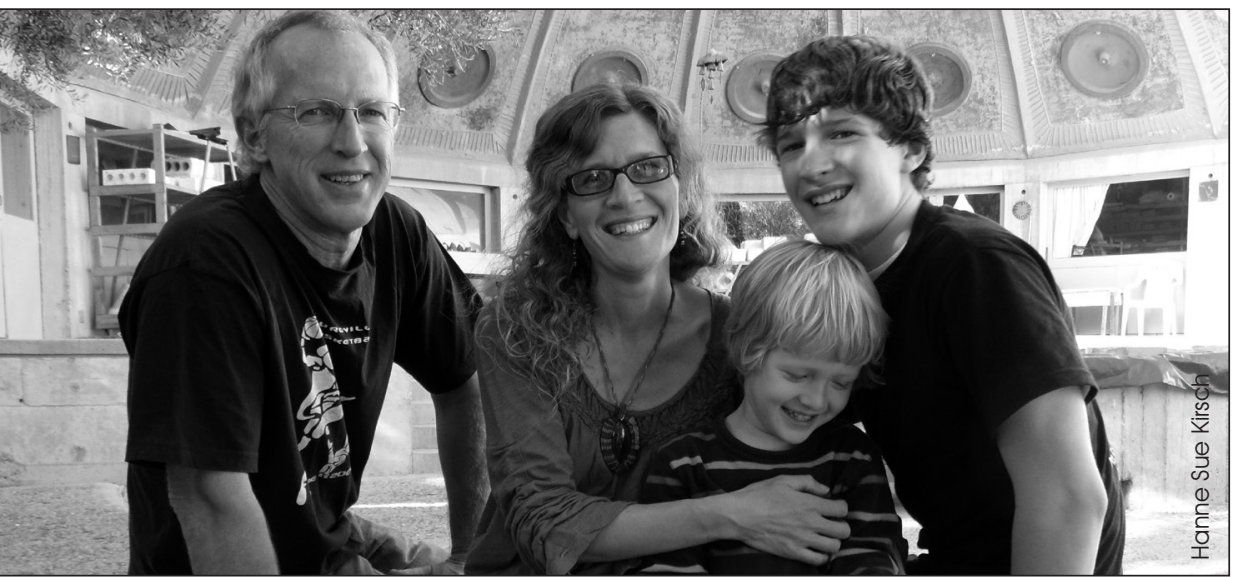

"Becoming" might be the operative word, as the vision of Arcosanti 5000 is no closer to reality than it was when Stein worked on the Cosanti Foundation staff decades ago. Currently, Arcosanti has roughly 80 permanent residents, and living spaces are limited.

Nadia Begin, an architect and planning coordinator at the project for almost 18 years, gave birth to two sons in her humble apartment on the grounds. She and her husband, project manager of the new greenhouse, dream of an Arcosanti with increased living spaces and a more welcoming environment for families. (Aside from their two boys, one other child lives at the complex.)

David Tollas, project manager of the new greenhouse, and his wife, -architect Nadia Begin, head of the planning department at Arcosanti, with their two children, Sasha and Tristan

I enjoy what it is, as it is, but I'm all for growing and developing it into an urban center —Nadia Begin

\section{Jeff Stein's First Experience at Arcosanti}

Jeff Stein was recently elected president of the Cosanti Foundation to replace the retired Paolo Soleri. He also served on the staff of the foundation from early 1975 through 1982. For Stein, those years constituted a time of great energy and construction activity at Arcosanti, and he developed a real appreciation for the power of the architectural idea. The following is an essay he wrote about those days, which helps shine light on why he decided to leave his prestigious post as dean of the Boston School of Architecture and return to the urban laboratory in the Arizona desert known as Arcosanti. (The essay was published in the book, Voices of Arcosanti, edited by Michel Sarda (Cosanti Foundation 2009)]

Fresh from graduate school in early 1975, I signed on to a six-week construction workshop at Arcosanti, Arizona, anxious to take my first trip to the American Southwest. Eight years later, I left Arcosanti for Boston. In between were some of the most rigorous, challenging, creative, joyful days of my existence.

The world's most beautiful construction site-Arcosanti-is perched on the edge of a mesa 70 miles north of Phoenix, in the high desert of Central Arizona. For the 80 or so people who live there year-round, it provides a kind of fishbowl existence. The staff is constantly training amateurs to draw, dig, build, accomplish the work itself, all surrounded by tourists every day. Back when I was there every day, making models, stripping concrete forms, learning crane signals, welding window frames, we engaged in deep simultaneous discussions about the future of the city, about how (back then) to predict solar gain with 1,500 computer punch cards, about people living near where they work, about budgeting time to wade into the sewage treatment oxidation pond to harvest water hyacinths, experiencing through the work how everything connects to everything.

Work was often interrupted by visitors: presidential candidates and politicians looking for the future and for great photo backdrops. I met Betty Friedan there. Jerry Brown came to spend the week and left with ideas that later formed the core of the California Urban Imitative. Performing arts events at the construction site provided a home away from home for Jackson Browne, Richie Havens, Paul Winter, and other musicians, performers, and thinkers. Paul Earls and Otto Piene came out from the MIT Center for Advanced Visual Studies. Architects arrived: I first met Phillip Johnson at Arcosanti. He, like me, like thousands of people since then, was drawn to the work and the optimistic personality of its originator, Paolo Soleri.

After a while the extraordinary became the norm. A television crew from Japan would show up, or a group of BBC journalists on a tour of the United States (they still do). They'd always begin, "We are here in the desert where a small group of people are reinventing the city." We DID think we were doing that in our heart of hearts. Yet the whole idea was so far-fetched that we seldom uttered it. We wouldn't take ourselves that seriously. Instead we awoke to the sound of wind bells, a morning construction meeting, and hearty meals right out of Arcosanti's extensive organic gardens. And of course there was the design and construction work itself, every day, something we did indeed take seriously. It was a balanced and complex life, urbane and frugal in the extreme. It's not so different even now.

At an Arcosanti conference in 1981, architect, critic, President of the Boston Architectural College Peter Blake sat with me on the edge of a cliff, overlooking the curving forms of the construction site in the near distance. "You're ready to move to Boston," he said. "Finish your architecture education; find your own voice in architecture." Bostonian Ron Gourley was seated next to him. Then dean of the School of Architecture at the University of Arizona, where I had been a student, and a frequent visitor to Arcosanti, Gourley concurred. A year later I was living in Cambridge, Massachusetts. I had brought Arcosanti with me. As in one of Italo Calvino's Invisible Cities, I had only to glance at the night sky. "There's the blueprint," it says. 
"We're definitely hoping still, but without family, I don't know how it can grow," says Begin, whose 14-year-old son attends boarding school 10 minutes from the site. "I enjoy what it is, as it is, but I'm all for growing and developing it into an urban center. We obviously need a lot more housing and schools, but I do have hope that it can happen."

\section{Spreading the Word}

Despite Soleri's brilliance, the man never spent much time showcasing his ideas and accomplishments. But for Arcosanti to make a global impact, a little cheerleading is exactly what's needed.

"We really have to be a model influencing how cities are designed," Begin asserts. "We cannot just be here building this. We have to be a part of what's going on as people are discussing sustainability."

That's where Stein, after a high profile career as the dean at the Boston Architectural College and Wentworth Institute of Technology, must play a pivotal role. Begin and her colleagues are encouraged by the progress under Stein's leadership over the past seven months, and they hope his experience in management and networking will help ensure that their work is included in the greater sustainability dialogue.

Nationally, Stein and his team are collaborating with several colleges and universities to provide opportunities for students to participate in the Arcosanti workshops. More than 100 colleges in the United States grant academic credit to students who participate in the Arcosanti workshops, and the dean of neighboring Northern Arizona University (NAU), a school that's made sustainability central to its educational mission, has helped develop a series of projects for NAU students to work on at the site.

Stein also believes college campuses would make a good starting point for following the arcology model given that these communities already exist in condensed living environments.

But to truly construct a city under the principles of arcology would seem next to impossible for most urban communities in the Western world, and certainly in the United States. Stein doesn't see the task as all that difficult from an architectural point of view; there's just the small matter of people completely changing their habits and ceasing to conduct business as usual, both in lifestyle choices and how buildings are constructed.

"Architecture is really in the transformation business rather than the sustaining business," Stein points out. "Even now, when you design a new building, you've just traded a bunch of nature for it. You scrape all the

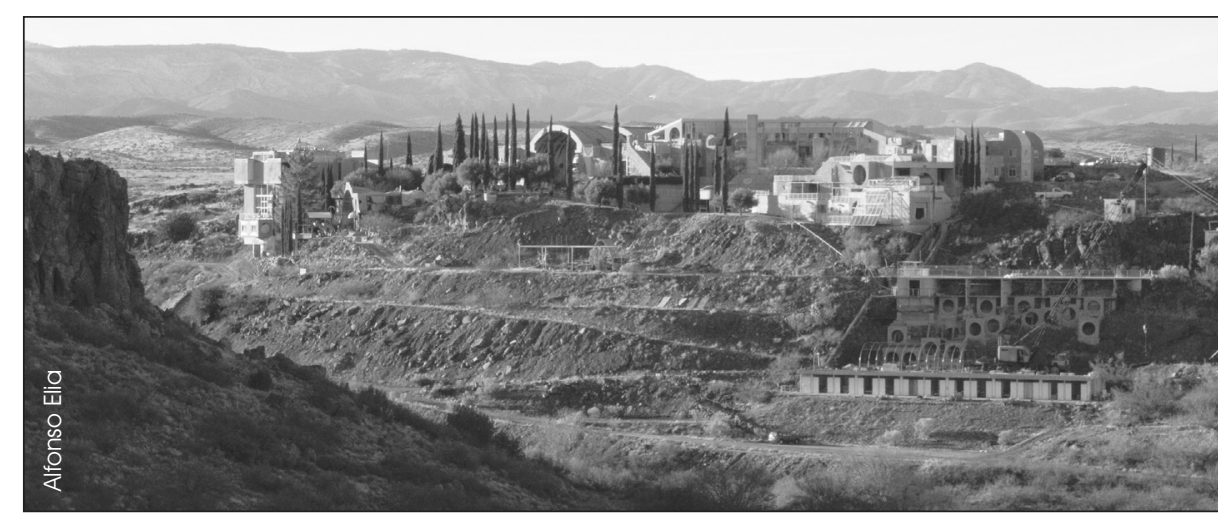

life off a piece of ground, and you make a building of dead materials."

As Stein is discovering through his networking efforts, however, some developing countries are receptive to changing their ways. "There's quite a bit of interest from China, which at this time in the history of the world, has the economy and the political will to do something like this," Stein says. "There's also a couple of corporations on a global scale that are beginning to be interested in helping to develop this sort of thing, so we'll see where it goes."

The big-picture goal is to help governments and other institutions worldwide develop cities in alignment with the vision of arcology. But that can't happen until the model town in the desert is realized.

"When all of our large cultural artifacts were designed and built-our buildings, schools, shops, factories, highways-we had no idea at all how the earth actually works," Stein says. "Now that we're getting to find out, it's going to take a lot more than just reforming all of these things we've already built. It's going to take a reformulation of how we live on the earth.

"And that's one of the reasons we're going so slowly about it here at Arcosanti. We've been doing this stuff for 40 years, and we're still doing it, which is pretty great. Kind of like the slow food movement, we're the slow architecture movement. But this reformulation is mighty complex."

\section{The Night Sky}

The excitement in Stein's voice rises as he paints the scene of the Sky Theater, a construction of concrete bleachers on the roof of the East Crescent complex. The theater, built ergonomically to fit the human body, allows star gazers to tilt back comfortably as they absorb the Milky Way from their desert perch, some 3,700 feet above sea level.

This season, one could catch a glimpse of Orion's Belt, the Pleiades, or, with the right luck, a meteor
Arcosanti, view from east of the city

The world's most beautiful construction site-Arcosantiis perched on the edge of a mesa 70 miles north of Phoenix. -Jeff Stein 


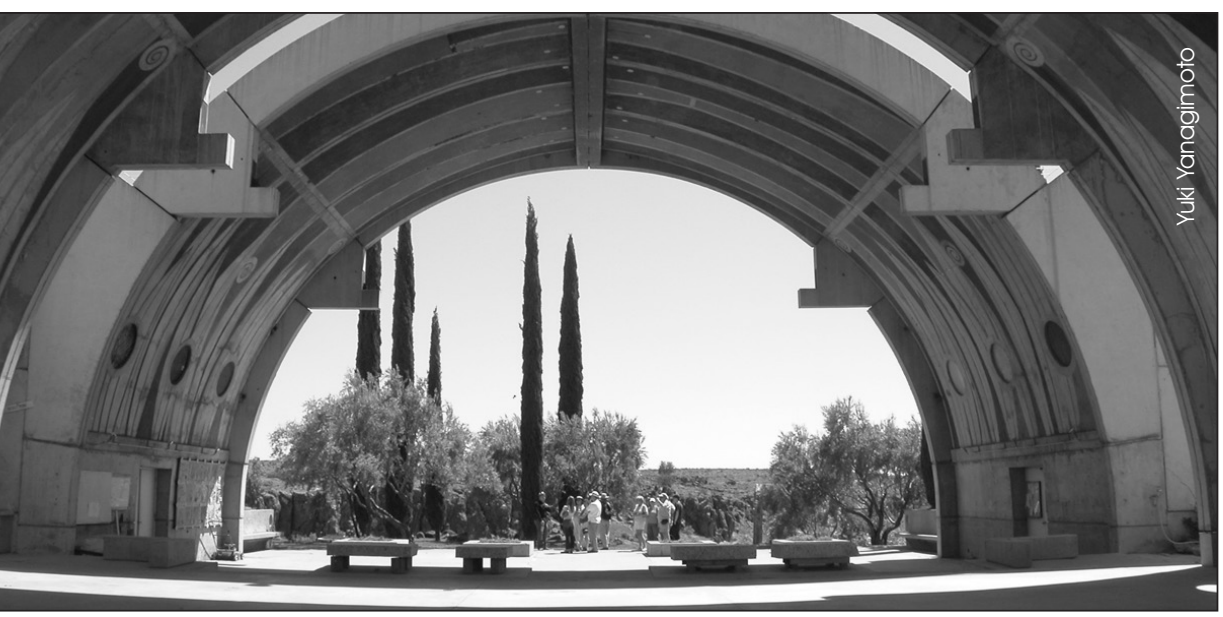

shower. For the 50 percent of the earth's population now living in urban areas, that's an elusive picture. But it's a visual that might just break 21st century society from the bad habits that have led to the ongoing environmental crisis; if only people were able to get the chance to see what Stein is privileged to experience every day in the desert.

"It's just fantastic to be part of a community here, and yet have this close connection not only to the rest of the earth around us, but to the sky itself," Stein says. "It's really something that so many people miss and deserve to experience. And you can experience it here, of course. But you should be able to do this a lot more places."

Arcosanti vaults viewed from the north. The vaults are the midpoint of the Arcosanti site and design.

This large public area provides space for events and meetings.

It's just fantastic to be part of a community here, and yet have this close connection not only to the rest of the earth around us, but to the sky itself.

-Jeff Stein

\section{Arcosanti Workshops*}

Since 1970, the Arcosanti Workshops have combined academic and experiential learning as participants study Paolo Soleri's concepts and designs while contributing to the building of the arcology (architecture plus ecology). Soleri proposes a lean urban alternative, which is a highly integrated and compact model rejecting the need for urban sprawl with its inherently wasteful consumption of land, energy, time, and human resources. During the Five-Week Workshop participants come to understand the world's first prototype of arcology.

\section{Week 1: Seminar Week}

Seminar Week is an introduction to the theory and concepts of Paolo Soleri. Participants have two informal seminars with Soleri and attend presentations by other Arcosanti staff on Arcosanti design development, construction history and future plans, and arcology theory. The week also includes extended tours of the built site including residential interiors, a half-day hike through the natural area surrounding the site along the Aqua Fria River, and a siltcasting workshop. Participants may enroll in Seminar Week independent of the other workshops. For Five-Week Workshop participants Seminar Week provides a detailed introduction to their stay at Arcosanti.

\section{Week 2: Field Trip and Work Opportunities}

During the second week of the Five-Week Workshop, participants have the opportunity to take a field trip to the Phoenix metropolitan area, stay at Cosanti (Soleri's original studios located in Scottsdale, AZ, and started in the mid-1950s) and at times assist with small ongoing projects there. They visit Frank Lloyd Wright's Taliesin West and other architectural sites of interest in the area. Participants also get an in-depth look at the work of various departments at Arcosanti as they participate in occasional work projects. Participants may enroll for two weeks in Seminar Week and Week 2. For Five-Week Workshop participants Week 2 exposes them to the scope of work being undertaken at Arcosanti. A meeting with Soleri continues in Week 2.

\section{Weeks 3, 4, and 5: Hands-on Intensive}

During the last three weeks of the workshop, participants work in different departments such as construction, facilities maintenance, agriculture, archives, or groundskeeping/landscaping, depending on Acosanti priorities at that specific time. Participants will also rotate through café and recycling duties with other Arcosanti residents. These three weeks also include occasional meetings with Paolo Soleri.

Workshop Start Dates in 2012: February 5 • March 11 • April 15 • May 20 • June 24 • July 29 September 2 • October 7 • November 11

Prerequisites: Previous construction or architectural knowledge is not a prerequisite for participation in our program. However, individuals must be at least 18 years of age or accompanied by a parent or a responsible adult to attend the program.

Further Information: For tuition information and other information requests, contact the Workshop Coordinator at 928-632-6233 or workshop@arcosanti.org.

*Information courtesy of Arcosanti.org 